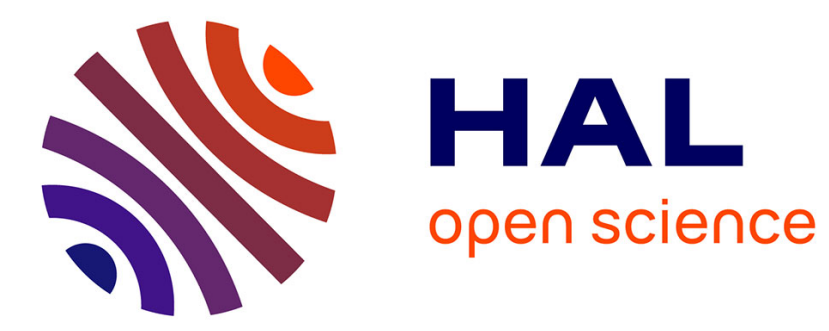

\title{
Vigour, pruning, and cropping in the grapevine (Vitis vinifera L.). II. Experiments on vigour, pruning and cropping
}

\author{
Max Rives
}

\section{- To cite this version:}

Max Rives. Vigour, pruning, and cropping in the grapevine (Vitis vinifera L.). II. Experiments on vigour, pruning and cropping. Agronomie, 2000, 20 (2), pp.205-213. 10.1051/agro:2000120 . hal00886007

\section{HAL Id: hal-00886007 https://hal.science/hal-00886007}

Submitted on 1 Jan 2000

HAL is a multi-disciplinary open access archive for the deposit and dissemination of scientific research documents, whether they are published or not. The documents may come from teaching and research institutions in France or abroad, or from public or private research centers.
L'archive ouverte pluridisciplinaire HAL, est destinée au dépôt et à la diffusion de documents scientifiques de niveau recherche, publiés ou non, émanant des établissements d'enseignement et de recherche français ou étrangers, des laboratoires publics ou privés. 


\title{
Review article
}

\section{Vigour, pruning, and cropping in the grapevine (Vitis vinifera L.). II. Experiments on vigour, pruning and cropping}

\author{
Max RIVES* \\ INRA, Station de Recherches de Viticulture, B.P. 81, 33883 Villenave d'Ornon, France
}

(Received 1 April 1999; accepted 31 October 1999)

\begin{abstract}
This second part of our review presents a synthesis of various experiments conducted in Bordeaux to look for an objective control for pruning in experimental work on the grapevine. This work was based on the published literature, as mentioned in the first part of this study. The concept of a pruning scale providing the load to be left on each vine at pruning as a function of the weight of the pruning woods it produced (a criterium of vigour) has been investigated.
\end{abstract}

grapevine / pruning / vigour / yield

Résumé - Vigueur, taille, production chez la vigne : II. Expériences sur la vigueur, la taille et la production. Cette seconde partie de notre synthèse porte sur des essais concernant l'établissement et la mise en pratique d'échelles de taille, donnant la charge en fonction du poids des bois de taille (mesure de vigueur) pour chaque plante de vigne, fournissant une technique qui supprime le facteur subjectif du tailleur dans les essais sur cette espèce.

vigne / taille / vigueur / production

\section{Introduction}

The literature shows that in the grapevine, the unit of production is the bud left at pruning; hence the importance of the load, which determines not only the following year's yield, but also the future evolution of the vine. The load is normally determined in a subjective manner by the pruner, therefore in order to eliminate this subjective factor in

Communicated by Silviero Sansavini (Bologna, Italy) and Hervé Thiellement (Geneva, Switzerland)

* Correspondence and reprints: 33 rue des Mésanges, 30400 Villeneuve-lez-Avignon, France rives@interlog.fr 
experiments, it is necessary to devise a means to make it objectively determined. The experiments described in this review investigated these points.

\subsection{Influence of the pruning load}

In order to study what actually takes place in the field, we have performed 2 field experiments $[7,8]$.

\subsection{Influence of the load left by the grower}

\subsubsection{Materials and methods}

Counts of buds and bunches were made just before flowering in April 1961 in a cane-pruned commercial Chasselas vineyard. Data was based on 1128 canes bearing 8 to 15 buds at pruning. Pruning had been done by the grower.

\subsubsection{Results}

Figure 1 depicts the results of our first investigation. It shows the mean fertility (average number of inflorescences present, or real fertility after Bessis [2]) on the first (basal) 4 buds of Chasselas canes retained at pruning as a function of the load, or total number of buds left on these canes.

Table I shows the analysis of variance of the regression of the mean fertility of the first 4 buds on the total number of buds on the cane.

The decrease in mean fertility, as measured by the regression coefficient of the straight line through the points, is highly significant and there is no further variation (deviations from the straight line) worth mentioning.

\subsubsection{Discussion}

We have here assumed that pruning was random vis à vis vigour in this case. This means that the expectation of potential fertility (in initials per bud) was assumed to be the same for all 1128 canes, with no difference among the samples for the various loads other than random sampling variation. It is important to stress that our assumption on the absence of difference between the various samples of canes before pruning is confirmed by the results: if the pruner had taken the vigour of the canes into account to adjust the load he left on each cane, the reverse result would have been obtained

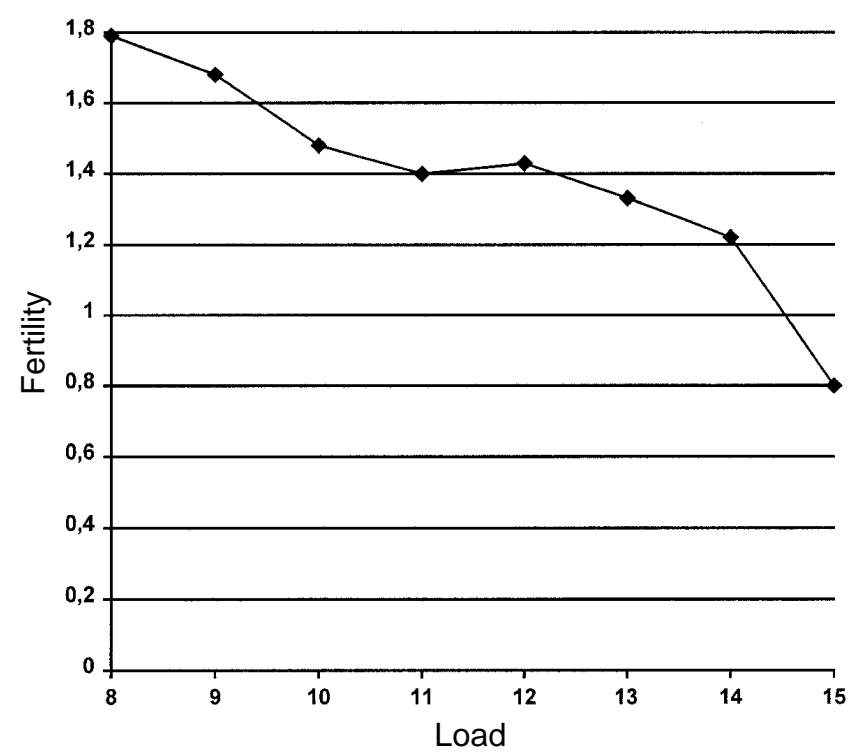

Figure 1. Fertility versus load in Chasselas vines. 
Table I. Analysis of variance of regression for fertility in first 4 buds on total load of cane.

\begin{tabular}{lccccc}
\hline Source of variation & Sums of squares & D.f. & Mean squares & Observed F & F 0.01 \\
\hline Total & 530 & 1127 & & & \\
Loads & 157 & 11 & 11.00 & 24.1 & 6.64 \\
Regression & 4 & 6 & 0.70 & 1.5 & 2.80 \\
Deviations & 515 & 1120 & 0.46 & \\
Residual & & & & \\
\hline
\end{tabular}

as the more loaded, the more vigorous canes would have hence been the more fertile.

A second piece of evidence is provided by the variation in percentage bud burst of these 4 basal buds as a function of the load of the cane: Figure 2 shows that there was a sharp decrease in this percentage with load which is attributed to a bad fit between pruning load and vigour. The overall percentage of burst on the canes (Fig. 3) dropped from $89.5 \%$ for 8 -bud canes to $70.5 \%$ for 15 -bud canes.

Thus, while fertility remained the same in all vines on the average, overloading resulted in the loss of a part of the initials that was roughly proportional to the load.

\subsection{Influence of the load left according to balanced pruning}

\subsubsection{Materials and methods}

In our second experiment, also performed in a commercial Chasselas vineyard, we made use of the technique of "balanced pruning" the development of which shall be described later. This consists of determining the load left on each vine according to a scale associating a class of pruning weight with a given number of buds left. Table II shows the scale we used. Counts were made in a similar manner.

\subsubsection{Results}

One should note that with this scale in the same variety, i.e., Chasselas, the actual load extends beyond the maximum used by the grower in the previous experiment, thus increasing the probability of an eventual overloading effect.

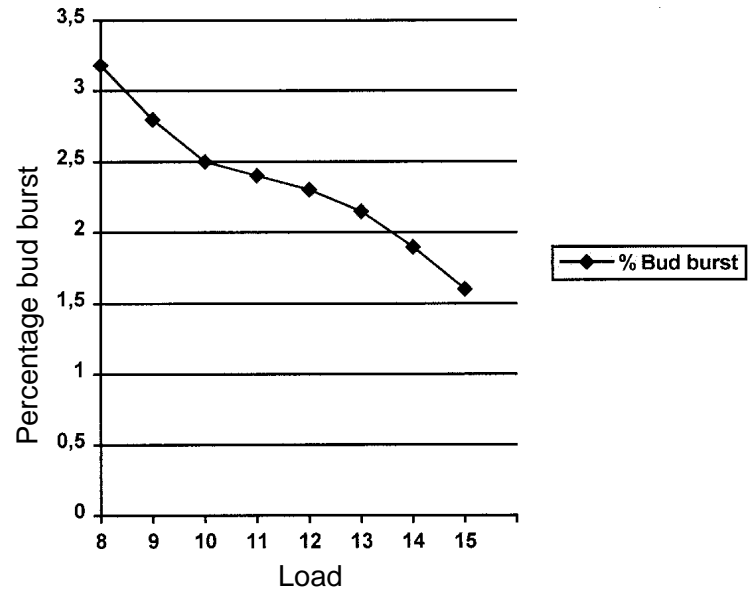

Figure 2. Percentage bud burst among basal buds versus load in Chasselas vines.

Table III gives the results of 2 years' observation in terms of mean fertility of the first 4 buds, number of buds that had actually grown out among these first 4 buds, and percentage bud burst on the whole cane.

\subsubsection{Discussion}

The contrast with the figures from the first experiment is striking. The between- column differences are obviously within the limits of random variation for all measurements.

There are buds that do not burst, and it is likely that this is more pronounced at the base due to inhibition from apical dominance (from the first top buds of the cane that do burst first as a rule). But here we have very significant evidence in 
Table II. Scale of load according to pruning weight (Chasselas vines experiment).

\begin{tabular}{lccccc}
\hline Pruning weight & Load & Pruning weight & Load & Pruning weight & Load \\
\hline $50-600$ & 6 & $950-1000$ & 10 & $1350-1400$ & 14 \\
$650-700$ & 7 & $1050-1100$ & 11 & $1450-1500$ & 15 \\
$750-800$ & 8 & $1150-1200$ & 12 & $1550-1600$ & 16 \\
$850-900$ & 9 & $1250-1300$ & 13 & $1650-1700$ & 17 \\
\hline
\end{tabular}

Weighing was to the nearest $50 \mathrm{~g}$.

Table III. Second Chasselas vines experiment.

\begin{tabular}{lcccccccccc}
\hline Load & 5 & 6 & 7 & 8 & 9 & 10 & 11 & 12 & 13 & 14 \\
\hline Fertility & 1.98 & 2.37 & 2.04 & 2.34 & 2.32 & 2.37 & 2.03 & 2.19 & 2.08 & 2.21 \\
& 2.00 & 1.95 & 1.80 & 1.82 & 1.57 & 2.25 & 2.16 & 1.92 & 2.07 & 2.02 \\
BB4 & 3.40 & 3.61 & 3.36 & 3.30 & 3.50 & 3.33 & 3.29 & 3.25 & 3.14 & 2.71 \\
& 3.55 & 3.31 & 3.15 & 3.31 & 3.30 & 2.25 & 3.30 & 2.77 & 3.05 & 3.18 \\
BBLW & 88 & 92 & 90 & 91 & 93 & 92 & 92 & 93 & 88 & 91 \\
& 90 & 86 & 87 & 90 & 92 & 92 & 90 & 75 & 81 & 83 \\
\hline
\end{tabular}

Fertility: mean number of clusters on the shoots issued from the first 4 buds of the long wood; BB4: average number of buds having burst among the first (basal) 4 on the long wood; BBLW: average percentage bud burst over all buds of the long wood. Top line in each row: 1965; bottom line: 1966 .

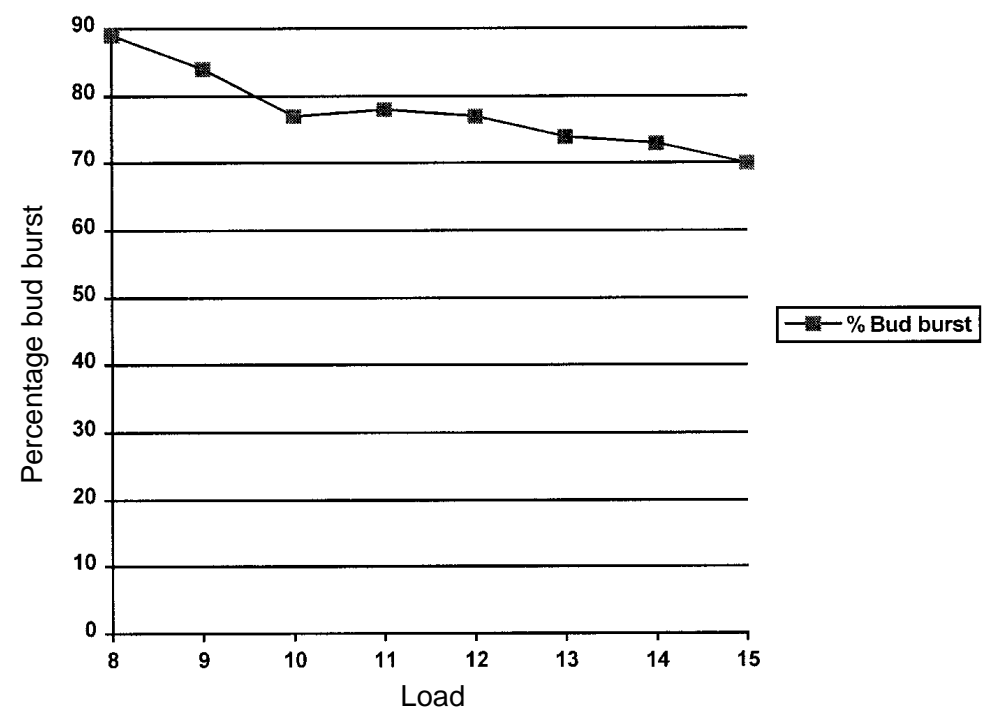

Figure 3. Percentage bud burst on whole cane versus load in Chasselas vines. 
support of the theory that, as viticultural tradition holds, but seldom puts into practice, pruning load should be determined in proportion to the vigour of the vine.

\section{The concept of balanced pruning}

Boubals [1] has clearly expressed this last view in the case of vines trained in goblet with spurs in the Mediterranean region of France: "A goblet with spurs can be considered as correctly pruned when the load left is such that in the following growing season, there are no suckers on the arms and trunk, and that in the next winter, the spurs that can be left on the vine are of the same diameter as those left in the preceding year".

Here we find vigour expressed in terms of the diameter of the canes, and a criterion of good balance of pruning, the absence of suckers, or shoots originated from latent buds in the old wood, that are induced to growth when the load is not sufficient with regard to what the vigour would permit the vine to bear. We have already come across the reverse effect, when buds fail to burst as the load is too heavy. One should note, however, that suckers are not as good a symptom of underloading in Guyot-trained vines as they are on goblets.

Shaulis et al. [9] and Winkler [10], reporting on pruning trials, have recommended that some proportionality be used to determine the number of buds left at pruning on the vines, especially with the hybrid varieties grown in New York state. They do not, however, report on experiments aiming at establishing such scales in an objective manner. Boubals [1] implicitly advocates adopting the same procedure.

As we have seen in the first Chasselas trial, it does not seem that growers really do enforce this recommendation.

\subsection{Investigating empirical pruning scales [6]}

In order to check on this point, and as a preliminary to experiments aimed at establishing pruning scales and providing a rational and objective basis to pruning, we observed what the members of the field team at our experimental farm actually did.

\subsubsection{Materials and methods}

In the first part of the experiment, 10 field workers at our experimental farm were each assigned a row of Merlot vines and requested to prune these according to their own judgement (as is normally the case in the vineyard at the farm). The prunings were harvested vine per vine, labelled and weighed. The load left for each vine was then counted and recorded, and the correlation coefficients calculated from this data.

In the second part of the experiment, two colleagues followed a similar technique on one and the same set of randomly selected vines in another part of the field. Without actually pruning, each individual announced the load he would leave; I recorded this information whilst I observed how they operated. After pruning, the prunings were weighed and the correlations were then calculated

\subsubsection{Results}

The data for the first part is listed in columns 1 to 10 of Table IV. There were 63 to 67 degrees of freedom due to missing vines. The significant value of $\mathrm{r}$ at $\mathrm{P}=0.05$ is 0.25 ; at $\mathrm{P}=0.01$ it is 0.32 . Although not entirely poor, with 4 out of 10 not reaching $\mathrm{P}=0.05$, the results show only a limited trend in the right direction.

The observations made regarding my colleagues, noted previously, showed that one of them based his decision almost exclusively on the diameter of the canes, while the second also took into account their total number. (In doing so, some memory of the load left during the preceding winter possibly corrected by the failure to burst of some buds in the case of overloading may have been taken into account.) Using $B$ for pruning weight and $\mathrm{S}$ for the number of canes, the correlations in Table $\mathrm{V}$ were obtained. In this table, the difference between techniques is obvious. The score of pruner 12 at 0.88 probably represents the maximum that it is possible to achieve through 
Table IV. Correlations observed between load and weight of prunings made by 10 staff members of the labour team.

\begin{tabular}{|c|c|c|c|c|c|c|c|c|c|c|}
\hline \multicolumn{11}{|c|}{ Staff member No. } \\
\hline & 1 & 2 & 3 & 4 & 5 & 6 & 7 & 8 & 9 & 10 \\
\hline $\mathrm{r}_{\mathrm{CB}}$ & 0.32 & 0.24 & 0.22 & 0.34 & 0.19 & 0.44 & 0.37 & 0.20 & 0.65 & 0.63 \\
\hline
\end{tabular}

simple visual evaluation, accounting as it does for $0.78 \%$ of the total variance in this decision.

This supports the assumption that only very skilled operators, who fully understand the meaning of adjusting the load to the vine vigour actually do achieve the goal that is prescribed by viticultural tradition and rational theory, i.e., that of adjusting load to vigour.

From both the commercial and the experimental point of view, adjusting load in this manner through what I have called "balanced pruning" proves to be extremely important.

\section{Comparison of pruning scales [6]}

To evaluate the importance of the effect of varying the pruning scale, we first performed a trial comparing 3 such scales. Scales can differ in the slope of the relation between pruning weight and load, or by the ordinate at the origin of a straight line, or both. In this study, linear relations between load and pruning weight were used.

\subsection{Materials and methods}

Table VI shows the scales that were selected, differing by the ordinate at the origin. The experimental design involved 792 vines taken from a plot of Merlot. We first allocated each vine (excluding young vines resulting from replacement), to one of 3 classes (I, II, III) according to their pruning weight, as shown in Table VII. We then allocated at random groups of 3 vines I, II, III, as they were found in the field, to 3 lots of vines A, B, C. Each lot finally numbered 264 vines. In this way, we constituted 3 samples of vines in the vineyard that
Table V. Correlations observed for 2 senior members of staff.

\begin{tabular}{cccccc}
\hline & & \multicolumn{5}{c}{ Staff member No. } \\
& & 11 & & & 12 \\
& B & & S & B & S \\
\hline C & 0.58 & 0.53 & 0.88 & 0.35 \\
B & & & 0.33 & & 0.33 \\
\hline
\end{tabular}

B: weight of prunings; S: No. of canes; C: remaining load.

Table VI. Three pruning scales.

\begin{tabular}{lccc}
\hline Pruning weight & Load A & Load B & Load C \\
\hline$<250$ & 2 & 4 & 6 \\
$251-300$ & 3 & 5 & 7 \\
$301-400$ & 4 & 6 & 8 \\
$1801-1900$ & 19 & 21 & 23 \\
$1901-2000$ & 20 & 22 & 24 \\
\hline
\end{tabular}

Table VII. Classes (I,II,III) of pruning weights in comparative scales.

\begin{tabular}{lc}
\hline I & $\mathrm{B}_{63}<350$ \\
II & $400<\mathrm{B}_{63}<950$ \\
III & $1000<\mathrm{B}_{63}$ \\
\hline
\end{tabular}

$\mathrm{B}_{63}$ represents the weight of prunings in 1963 to the nearest $50 \mathrm{~g}$.

Table VIII. Comparison of means and variance of distribution of vines in the pruning scales experiment.

\begin{tabular}{lcc}
\hline Sample & $\mathrm{B}_{63}$ & $\sigma_{\mathrm{B}_{63}}$ \\
\hline $\mathrm{A}$ & 560.6 & 15.49 \\
$\mathrm{~B}$ & 556.1 & 15.47 \\
$\mathrm{C}$ & 560.2 & 15.84 \\
\hline
\end{tabular}

$\mathrm{B}_{63}$ represents the mean of the pruning weight of the sample for 1963. 
had almost identical means and variances (see Tab. VIII). (It should be noted that each of the 3 lots comprised an equal number of vines from each of the 3 classes, which may not be a true reflection of the actual distribution in the vineyard.)

Each lot was then pruned according to one of the load scales shown in Table VI. In practice, each vine was pruned, leaving spurs and canes at full length for the Guyot training; the prunings of each vine were then bundled, labelled and weighed; from this the load for each vine was determined from the scale, and applied by pruning back the canes to their determined load.

\subsection{Results}

The results shown in Table IX illustrate the significant impact that even small differences in the pruning scale applied can have on the production of the vines.

$\mathrm{C}$, the load, was the direct result of $\mathrm{B}$, the weight of the prunings, through the application of the pruning scale. It can be seen that the difference in ordinate of the scales was almost exactly reflected in $\mathrm{C}$ for the 3 samples. In the same manner, the difference in load was reflected in the number of clusters, Gr, found on the vines This resulted in very large differences in yield among the 3 treatments (58\% in $1964 ; 73 \%$ in 1965). At the same time, while it is noteworthy that the overall weight of prunings remained unchanged and even seemed to follow the same trend as the load, the mean individual weight of the canes decreased markedly by the sharing of the "vigour" among more canes, which presumably corresponds to their diameters having also decreased. It can also be mentioned that the sugar content of the crop was the same for all 3 treatments in both years (data not shown).

\subsection{Discussion and conclusion}

The first conclusion is that pruning is of utmost importance in determining the yield to come in the following year. This can, however, bias experiments. It can make an experiment determine whatever one (or chance) wishes. Even with none the least intention of biasing the trial, it is well known that being aware of the possible outcome can unconsciously influence the operator. While we have seen that the fit between vigour and what an average pruner achieves is far from being satisfactory, even random departures from the relation that ought to exist between pruning weight and load will simply increase the error variance, at the expense of the quality and efficiency of the experiment.

Although the figures suggest a decrease in vigour, I am of the opinion that this is entirely attributable to the environmental differences between the years, especially as the slight trend for $\mathrm{B}$ to increase from one scale to the other in both years would be in the other direction, should an adverse effect have occurred. The marked decrease, however, in the mean weight of a cane in 1965 (20\%) indicates that the fertility in 1966 would have been lower in vines of sample III, thus decreasing the expected yield. This experiment, however, does not permit conclusions to be drawn on this point.

Table IX. Results of the experiment on comparison of pruning scales.

\begin{tabular}{lcccccccccc}
\hline Scale & $\mathrm{B}_{63}$ & $\mathrm{~B}_{64}$ & $\mathrm{~B}_{65}$ & $\Sigma_{65}$ & $\mathrm{C}_{64}$ & $\mathrm{C}_{65}$ & $\mathrm{P}_{64}$ & $\mathrm{P}_{65}$ & $\mathrm{Gr}_{64}$ & $\mathrm{Gr}_{65}$ \\
\hline I & 561 & 438 & 403 & 55 & 5.8 & 4.6 & 1515 & 652 & 10.9 & 7.5 \\
II & 556 & 443 & 411 & 47 & 7.8 & 6.6 & 2006 & 868 & 14.2 & 9.1 \\
III & 560 & 446 & 426 & 44 & 9.7 & 8.7 & 2390 & 1125 & 16.8 & 11.4 \\
\hline
\end{tabular}

B: mean pruning weight for that year (last data for the year); $\Sigma_{65}$ : mean weight for one cane in 1965; C: mean load in that year (first data for the year); P: mean yield in that year; Gr: mean No. of clusters in that year. 
It is interesting to note that the high yield of 1964 does not seem to have decreased the vigour of the vines in sample III, as compared to those in sample I. This and other data will lead us to consider the modes of competition between exports such as crop, and vigour such as stored carbohydrates.

From Table $\mathrm{X}$, it is possible to work out the average fertility for 1964 and 1965 , as well as the mean weight of a harvested cluster. The slight decrease in fertility in 1964 cannot reflect differences in inflorescence initiation, as the vines had been chosen in a random manner with regard to this trait. They probably reflect losses before flowering. The very slight increase in $\mathrm{p}_{64}$ is not significant. The differences in 1965, however, are likely to reflect the effect of differential pruning on fertility, as expected from the effect on the individual vigour of the canes. The marked increase in the individual weight of the clusters remains to be explained; it may result from a compensation for the sharp decrease in fertility. This in turn appears as the main consequence of the increase in the severity of pruning. In a "de-bunching" trial in the Medoc, $50 \%$ of the clusters were removed a few weeks after flowering. The resulting yield was approximately $80 \%$ of that of the control (data not shown). This shows that compensation - most likely in terms of the individual weight of the berries had taken place. These results provide the basis for more experimentation in this regard.

\section{General conclusion: determining pruning scales}

Theoretically, it would be advisable to determine an appropriate pruning scale for every situation: variety; rootstock; place.

To begin with, observing an established vineyard and how it is generally pruned will provide useful indications (see $\S 1$ and 2). One can count the load that is empirically left. In favourable cases, it will even be possible to weigh the prunings. Then it is possible to count the buds that have not burst and/or the number of suckers if present,
Table X. Fertility and mean weight of a cluster: results of the experiment on comparison of pruning scales.

\begin{tabular}{lcccc}
\hline Scale & $\mathrm{F}_{64}$ & $\mathrm{p}_{64}$ & $\mathrm{~F}_{65}$ & $\mathrm{p}_{65}$ \\
\hline A & 1.88 & 139 & 1.63 & 87 \\
$\mathrm{~B}$ & 1.82 & 141 & 1.38 & 95 \\
$\mathrm{C}$ & 1.73 & 143 & 1.31 & 99 \\
\hline
\end{tabular}

F: fertility; p: mean weight of a cluster.

or note their absence (the last in goblet vines, as trellised ones do not seem to respond as readily by emitting suckers). These observations will provide a rough estimate of the appropriate scale to apply. There remains, however, the question of devising a practical criterion for balance. Pending further investigations that might provide some indication of a quick and easy way of determining such a scale, I consider that the following technique, suggested by the first Chasselas experiment, might be contemplated at least to calibrate the scale for an experimental vineyard. This would involve repeating the second Chasselas experiment, with 3 scales instead of only one. Analysing the same traits would provide a test of the relative appropriateness of the scales.

It should be stressed that the really important factor with a scale such as that used in field trials is that it provides an objective means of determining the load for each vine which makes it independent of the experimenter and of the aims of the trial.

In vineyards that are trellised on wires, canopies overlap from one vine to the next. Competition for light between the foliage of adjacent vines is apparently responsible for the negative correlation that can be observed among consecutive vines on the row [5]. Such heterogeneity is not welcome in experimental trials. It may also be a nuisance in commercial vineyards, e.g., in rendering maturity heterogeneous. As previously mentioned, Shaulis [9] and Winkler [10] have recommended appropriate scales to avoid this phenomenon. Careful use of differential loading could be a means of correcting such heterogeneity, by overloading the vigourous vines and underloading the weak vines. 


\section{References}

[1] Boubals D., Un essai d'interprétation des résultats d'expérimentation vigne haute-vigne basse, Jour. CETA (Vit.) 615.

[2] Bessis R., Recherches sur la fertilité et les relations de croissance entre bourgeons chez la vigne (Vitis vinifera L.), thèse Dijon, p. 236, 1965.

[3] Bouard J., Recherches physiologiques sur la vigne et en particulier sur l'aoûtement des sarments, thèse Bordeaux, p. 345, 1966.

[4] Ravaz L., Taille hâtive, taille tardive, Coulet, Montpellier, 1912.
[5] Rives M., Description de l'hétérogénéité des champs d'expérience, Biometr. Zeitschr. 11 (1969) 113-122.

[6] Rives M., Castéran P., Leclair Ph., Observations préliminaires sur la détermination objective de la taille chez la vigne, C.R. Acad. Agric. 52 (1966) 537-544.

[7] Rives M., Hévin M., Le «filage» des grappes chez la vigne, C.R. Acad. Agric. 52 (1966) 478-482.

[8] Rives M., Hévin M., Filage, charge et vigueur chez la vigne, C.R. Acad Agric 52 (1966) 1062-1066.

[9] Shaulis N., Jordan N.J., Tomkins J.P., Cultural practices for New York vineyards, Cornell Ext. N.Y. St. Coll. Agric. Bull. 805 (1966) 3-47.

[10] Winkler A.J., General Viticulture, Univ. California Press, p. 623. 